\title{
The Role of Large-Scale Drivers in the Amundsen Sea Low Variability and Associated Changes in Water Isotopes From the Roosevelt Island Ice Core, Antarctica
}

\section{Daniel Bengt Emanuelsson ( $\nabla$ danem@bas.ac.uk)}

British Antarctic Survey https://orcid.org/0000-0002-9373-6951

James A. Renwick

Victoria University of Wellington - Karori Campus: Victoria University of Wellington

Nancy A. N. Bertler

Victoria University of Wellington - Karori Campus: Victoria University of Wellington

W. Troy Baisden

The University of Auckland Faculty of Science

Elizabeth R. Thomas

British Antarctic Survey

\section{Research Article}

Keywords: Climate variability, patterns of variability, Amundsen Sea Low, Southern Annular Mode, Pacific-South American patterns, the Antarctic sea-ice dipole, ice cores, water stable isotopes

Posted Date: January 24th, 2022

DOI: https://doi.org/10.21203/rs.3.rs-1215704/v1

License: (c) (i) This work is licensed under a Creative Commons Attribution 4.0 International License.

Read Full License 


\section{Abstract}

Here we examine the water stable-isotope data from the Roosevelt Island Climate Evolution (RICE) ice core. Roosevelt Island is an independent ice rise located at the northeastern margin of the Ross Ice Shelf. In this study, we use empirical orthogonal function (EOF) analysis to investigate the relationship between RICE ice-core oxygen-18 isotopes $\left(\delta^{18} 0\right)$ and Southern Hemisphere atmospheric circulation during the extended austral winter (April-November). The RICE $\delta^{18} \mathrm{O}$ record is correlated with Southern Annular Mode (SAM) and Pacific-South American pattern 1 (PSA1), which both project onto the AmundsenBellingshausen Sea (ABS) geopotential height field. Pacific sector Southern Ocean, eastern Ross Sea, and West Antarctic's atmospheric circulation, sea ice, and surface air temperature (SAT) anomalies, as well as RICE $\delta^{18} 0$, are strongest when El Niño-Southern Oscillation (ENSO) and SAM are "in-phase". That is when the SAM-/PSA1+ (El Niño) and SAM+/PSA1- (La Niña) phasing prevails. When in-phase, the $\delta^{18} \mathrm{O}$ correlation with the 500-hPa geopotential height (Z500) is strong in regions (e.g., the Amundsen Sea) where their anomalies associated with SAM and PSA1 show the same sign. SAM-/PSA1+ (EI Niño) and SAM+/PSA1 - (La Niña) is associated with positive and negative $\delta^{18} \mathrm{O}$ anomalies, respectively. RICE $\delta^{18} \mathrm{O}$ can aid in establishing past natural variability of the strength of the SH high-latitude Pacific sector ENSOSAM connection and associated atmospheric circulation, SIC, and SAT extremes.

\section{Introduction}

The Roosevelt Island Climate Evolution (RICE) ice-core drill site was located at the summit of Roosevelt Island $\left(79.362^{\circ} \mathrm{S}, 161.698^{\circ} \mathrm{W}, 550 \mathrm{~m}\right.$ a.s.l.). Roosevelt Island is a grounded coastal ice rise, located at the northeastern margin of the Ross Ice Shelf (Fig. 1). An intermediate-depth ice core (764 m) was drilled here over two southern summers (2011/2012 and 2012/2013) (Tuohy et al. 2015; Emanuelsson 2016; Bertler et al. 2018). Traditionally, ice-core oxygen-18 $\left(\delta^{18} 0\right)$ and deuterium ( $\left.\delta D\right)$ water stable isotopes have been used as palaeothermometers, i.e., proxies for reconstruction of past core site air temperatures (e.g., Dansgaard 1964; Masson-Delmotte et al. 2008; Stenni et al. 2017). Atmospheric circulation (Küttel et al. 2012), sea ice extent (Bromwich and Weaver 1983; Noone and Simmonds 2004; Küttel et al. 2012), and precipitation amount (Noone and Simmonds 2002) all affect the isotopic variability in Antarctic snow and ice. Variability and trends in West Antarctic SAT (Steig et al. 2009; Schneider et al. 2012) and water isotopes (Steig et al. 2013; Sinclair et al. 2014) have been linked to changes in atmospheric circulation and sea ice extent.

Southern Hemisphere (SH) extra-tropical circulation variability is to a large extent modulated by the Southern Annular Mode (SAM) and by Rossby wave propagation (called teleconnections) associated with the El Niño-Southern Oscillation (ENSO) and with the Indian Ocean Dipole (IOD) (Lim and Hendon 2017). SAM is the leading pattern of the large-scale atmospheric variability in the $\mathrm{SH}$ and has a strong impact on high latitude regions (Rogers and van Loon 1982; Thompson and Wallace 2000; Ding et al. 2012). SAM is characterized by a quasi-zonally symmetric pattern with geopotential height anomalies of opposite signs over the mid-latitudes and high-latitudes (positive SAM is associated with negative anomalies over 
Antarctica). The variability in the strength and location of the persistent circumpolar westerly winds surrounding Antarctica is closely linked to SAM. The Pacific-South American patterns (PSA1 and PSA2) are characterized by SH Rossby wave activity and are commonly defined as the second and third empirical orthogonal functions (EOFs) of the SH extratropical geopotential height field (Kidson 1988; Karoly 1989; Mo and Higgins 1998; Marshall and Thompson 2016). PSA1 is ENSO-related, and some studies have suggested that it can be viewed as an extension of ENSO into the SH (Karoly 1989). SAM and the PSA1 pattern both project onto the geopotential height field in the Amundsen-Bellingshausen Sea (ABS) region (Turner et al. 2013; Yu et al. 2015), affecting the state of the Amundsen Sea Low (ASL). The ASL is a marked climatological low-pressure center in the ABS/Ross Sea region that is present in annual and seasonal means of mean sea-level pressure (Turner et al. 2013; Raphael et al. 2015). The phasing of SAM and PSA1 can be in-phase or out of phase and act together to reinforce or cancel geopotential height anomalies, respectively, in the ASL region (Fogt et al. 2011; Yu et al. 2015). The PSA1 teleconnection with SH high-latitudes is strong during austral winter and spring (Turner 2004; Jin and Kirtman 2009). During the austral summer season, the SH circulation pattern is different from the rest of the year with a less pronounced ENSO high-latitude influence (Turner 2004).

Atmospheric circulation can cause both wind-driven and temperature-driven changes to sea ice, which in turn may affect $\delta^{18} O$. Further, Antarctic sea ice changes can affect atmospheric circulation and SAT (England et al. 2018). We focus on the extended-winter season (April-November) on the 500-hPa geopotential height (Z500, to represent large-scale atmospheric circulation), SAT and sea ice concentration (SIC) in our analysis to advance our understanding of their relation and impact on $\delta^{18} \mathrm{O}$.

\section{Data And Methods}

\subsection{Reanalysis and observational data}

We use monthly Z500, SAT and 850-hPa meridional (V850) and zonal (U850) wind data from the European Center for Medium-Range Weather Forecasts (ECMWF) Interim Reanalysis (ERA-Interim) dataset (Dee et al. 2011). ERA-Interim data $\left(0.75^{\circ} \times 0.75^{\circ}\right)$ are available for the $1979-2019$ period. The ERA-Interim data are considered the most reliable reanalysis products for the Antarctic climate (Bracegirdle and Marshall 2012; Jones et al. 2016). Since this research started, ERA5 reanalysis datasets have superseded the ERA-Interim. It is outside of the scope of the study to update all the analyses and the difference for this type of large-scale analysis is likely to be marginal. We use SIC from the Hadley Centre Sea Ice and Sea Surface Temperature datasets (HadISST v. 1.1) (Rayner et al. 2003). The monthly data $\left(1.0^{\circ} \times 1.0^{\circ}\right)$ is available from 1870 to the present. Observations from several sources are used to constrain the SIC dataset, e.g., sea ice charts and passive microwave satellite measurements. We limit our analysis to the common period between the RICE $\delta^{18} \mathrm{O}$ record and the satellite era, 1979-2011. For our analysis of the RICE $\delta^{18} \mathrm{O}$, we compute extended-winter (April-November (inclusive, here and for other extended-winter season parameters below)) seasonal averages from monthly ERA-Interim and HadISST 
data. The ERA-Interim fields are downscaled to a $1.0^{\circ} \times 1.0^{\circ}$ grid to get the same resolution of the datasets.

\subsection{Correlations, trends, and statistical analysis}

All data are detrended before linear Pearson's correlation coefficients $(r)$ are calculated. The significance level $(p)$ of the correlations accounts for lag- 1 autocorrelation by reducing the number of degrees of freedom (Bretherton et al. 1999). For significance levels of the correlations in Table 1 were assessed relative to synthetic noise from 1000 simulations with the same power spectra as the real data (Ebisuzaki 1997). Linear trends and regressions are calculated using the method of least squares and their statistical significance is determined using $t$ statistics and accounting for serial autocorrelation. For the composite analysis the significance of the difference between SAM-/PSA1+ and SAM+/PSA- states were determined using a two-sample t-test.

The significant tests are rigorous with both adjustments for temporal and spatial autocorrelation. We employ the false discovery rate (FDR) test to determine field significance (Wilks 2006, 2017) for composite differences, correlation and regression patterns. We set the $a_{F D R}$ to 0.1 (this level is also applied by e.g., Westra et al. (2015)), as this level approximately equates to a global significance level of $0.05\left(a_{F D R}=2 a_{\text {global }}\right)($ Wilks 2017).

\subsection{Empirical orthogonal functions}

Patterns of variability examined here were calculated using EOF analysis (Storch and Zwiers 1999; Deser et al. 2010) of the extended-winter (April-November) averaged monthly ERA-Interim Z500 anomaly field $\left(20^{\circ}-90^{\circ} \mathrm{S}\right)$ over the $1979-2011$ period. Prior to the EOF analysis, (1) the seasonal cycle is removed at each grid point by subtracting the corresponding monthly climatology, (2) the data is weighted using the square root of the cosine of latitude to provide equal weighting of equal areas, and (3) the linear trend is removed.

The ten first EOFs are determined and Varimax rotated. Rotation of EOFs geoscience data is recommended (Richman 1986). Only the two leading PCs are used. The two leading patterns of Z500 variability $\left(20^{\circ}-90^{\circ} \mathrm{S}\right.$; the SAM and PSA1 PCs regressed on to the $Z 500$ anomaly field) are shown in Figures $2 \mathrm{a}$ and $2 \mathrm{~b}$. They explain $34 \%$ and $20 \%$ of the $Z 500$ variability, respectively. PSA2 explains $9.8 \%$ of the total variance and the North et al. (1982) test shows that SAM, PSA1, and PSA2 are well separated (Fig. S1).

The extended-winter season was chosen as the season of the study because PSA1 teleconnection with $\mathrm{SH}$ high-latitudes is strong during winter and spring (Turner 2004; Jin and Kirtman 2009). More specifically the April-November season was selected as the $\delta^{18} 0$ correlation with PSA1 was strong and the leading EOF patterns were well-separable for this season. This seasonal circulation change in the ENSO teleconnection between the extended-winter season and the summer season is evident in the annual $\delta D$ correlation with the seasonal Z500 fields (Emanuelsson 2016), see their figure 4.10. However, 
broadly, the same results are obtained if annual means are employed, just with lower significance (not shown).

\subsection{The RICE water stable-isotope records}

The $\delta^{18} 0$ record used in this study consists of data combined from the RICE 2012/13 B firn core ( 1981.5-2011; 12.30-0.53 $\mathrm{m}$ depth; $79.362^{\circ} \mathrm{S}, 161.698^{\circ} \mathrm{W}, 550 \mathrm{~m}$ a.s.l.) and the uppermost part of the RICE Deep ice core (1979- 1981.5; 13.43-12.30 m depth; $79.364^{\circ} \mathrm{S}, 161.706^{\circ} \mathrm{W}, 550 \mathrm{~m}$ a.s.I.). The 12/13 $B$ firn core was drilled $93 \mathrm{~m}$ from the main RICE drill site. The RICE $\delta^{18} \mathrm{O}$ and $\delta D$ records were measured on a continuous-flow analysis (CFA) setup using a Los Gatos Research (LGR) Isotope Water Analyzer (IWA-35EP) (Emanuelsson et al. 2015). The age scale (depth-age relationship) used in this study was established by Winstrup et al. (2017). We use the $\delta^{18} \mathrm{O}$ in the subsequent analysis (Fig. 3a). However, our results are not dependent on whether $\delta^{18} \mathrm{O}$ or $\delta \mathrm{D}$ is used. An extended-winter $\delta^{18} \mathrm{O}$ record was created by averaging monthly means for $\delta^{18} \mathrm{O}$ and subsequently averaging over the April-November period. The monthly means are determined by linear interpolation between the age markers. However, the boundaries are approximate as we cannot claim monthly resolution of the $\delta^{18} 0$ record. A discussion of molecular diffusion's impact on the isotope record is provided in the supplemental material (Sect. S1).

\subsection{Computational procedure}

The analysis and visualization of the results were done in MATLAB 2020b. The analysis code is presented at the following Github page (https://github.com/demanuelsson). The ECMWF ERA-Interim (Dee et al. 2011) (http://apps.ecmwf.int/archive-catalogue/) and the HadISST SIC (Rayner et al. 2003) (http://www.metoffice.gov.uk/hadobs/hadisst/) datasets were accessed online.

\section{Results And Discussion}

\subsection{The SAM-PSA1 in-phase relationship and RICE $\delta^{18} 0$}

Strong positive $\delta^{18} 0$ correlations are found with the ASL $\left(r_{\max }=0.52, p<0.01,1979-2011\right.$; Figs. 3b-c), with high $Z 500$ being associated with high $\delta^{18} \mathrm{O}$ and low $Z 500$ with low $\delta^{18} \mathrm{O}$. Indicating that, atmospheric circulation in the ABS/Ross Sea Z500 (namely the ASL), is the driving force governing the extended-winter RICE isotopic signal (Fig. 3c). This is also reflected in the SAT and SIC correlation patterns (Figs. $3 d, e)$. Positive $\delta^{18} \mathrm{O}$ anomalies are associated with both positive SAT and negative SIC anomalies in the eastern Ross Sea (Figs. 3d, e). This pattern corresponds to the western flank of the anticyclonic circulation, where strong poleward meridional winds prevail. Resulting in airmasses that are isotopically enriched by the nearby open ocean north of the sea ice edge. Changes in sea ice also modify the sensible heat flux (the conductive heat flux from the ocean to the atmosphere) (Noone and Simmonds 2004). For example, when sea ice recedes (mechanically by wind and from melting associated with warm air mass intrusions), ice is replaced by open ocean leading to an increase in sensible heat flux followed by higher SAT. 
As both SAM and PSA1 project onto the ABS Z500 field (Turner et al. 2013), we next examine whether SAM and PSA1's phase relationship is preserved in $\delta^{18} \mathrm{O}$. The difference between SAM+/PSA1- and SAM-/PSA1+ years (marked by asterisk and circle in Fig. 4a, respectively) for Z500, SAT, and SIC is shown in Figure $4 b-d$. There is a striking similarity between the $\delta^{18} 0$ correlation panels (Figs. 3c-e) and the in-phase composite differences (Figs. $4 b-d$ ). These results show that $\delta^{18} O$ captures the SAM PSA1 in-phase relationship during the satellite era (Figs. $3 \mathrm{c}$ and $4 \mathrm{~b}$ ) as well as that the associated $\delta^{18} \mathrm{O}$ SAT and SIC patterns (see the Figs. $3 d, 4 c$ and $3 e, 4 d$ pattern pairs). Here positive $\delta^{18} O$ anomalies are associated with SAM-/PSA1+ and negative $\delta^{18} \mathrm{O}$ anomalies are associated with SAM+/PSA1- (Figs. 3a and 4a). The 2010 SAM+/PSA1- event was an exception; it was associated with a positive $\delta^{18} \mathrm{O}$ anomaly value.

In addition to the $\delta^{18} \mathrm{O}-\mathrm{Z} 500$ correlation, we depict regions where the SAM and PSA1 overlap in Figure 3c. The significant areas (encircled by black dashed contours in Figs. $2 a$ and $2 b$ ) are used to find regions of overlap. Here, the overlaid contours enclose regions where both patterns are active (significant at the $p<$ 0.05 level). The contours in Figure $3 c$ depict regions impacted by both the SAM and PSA1 modes, with the magenta contours showing regions where both modes display the same sign when the modes are inphase (or opposing signs when out of phase). Note that SAM and PSA1 are in-phase [SAM-/PSA1+ (EI Niño) or SAM+/PSA1 - (La Niña)] when they are associated with the same sign of the Z500 anomaly over the Amundsen Sea (Figs. 2a and 2b). This is consistent with Z500 PC1 (SAM) being negatively correlated and Z500 PC2 (PSA1) being positively correlated with $\delta^{18} \mathrm{O}$ (Table 1). Positive geopotential height anomalies over the Amundsen Sea/the eastern Ross Sea region [weak ASL and positive $\delta^{18} \mathrm{O}$ anomaly (Emanuelsson et al. 2018)] tend to be associated with SAM's negative phase and/or the PSA1 patterns positive phase (Fig. 3c). The region of SAM PSA1 overlap in the ABS/Ross Sea largely corresponds to the ASL region, as defined by Hosking et al. (2013) $\left(60^{\circ}-75^{\circ} \mathrm{S}, 170^{\circ} \mathrm{E}-70^{\circ} \mathrm{W}\right)$. Further evidence that the characteristic Rossby wave teleconnection pattern in the Pacific and Atlantic sectors is strengthened when SAM and PSA1 are in-phase (Fig. 3c).

Regions of significant $\delta^{18} \mathrm{O}-\mathrm{Z} 500$ correlations are characterized by either: (1) a region where both EOF patterns are significant and strengthen the correlation by showing the same anomaly sign when inphase., e.g., over the Ross and ABS (magenta contours, Fig. 3c); or (2) only one pattern is active (nonstippled and non-contoured areas), e.g., SAM over East Antarctica.

Furthermore, we have demonstrated that the EOF patterns SAM and PSA1 (that, are independent of RICE $\delta^{18} 0$ ) can explain the $\delta^{18} \mathrm{O}-\mathrm{Z} 500$ correlation pattern (see the overlain contours in Figure $3 \mathrm{c}$ ). Suggesting that the leading EOF patterns are real distinct large-scale dynamical modes and not degenerates, as some studies have cautioned (Dommenget and Latif 2002; Monahan et al. 2009).

The extended-winter RICE $\delta^{18} \mathrm{O}-\mathrm{SIC}$ correlation pattern shows high significance in the Amundsen/eastern Ross Seas region (Fig. 3e). The ABS SIC physically affects $\delta^{18} \mathrm{O}$, by dictating the distance to the open ocean. The positive correlation with SIC in the Bellingshausen Sea and the Weddell Sea reflects the 
Antarctic Dipole Pattern (ADP) (Yuan and Martinson 2000; Renwick 2002; Yuan 2004; Turner et al. 2009; Thomas and Abram 2016), caused by the ASL creating opposing SIC anomalies between the Pacific and Atlantic sectors.

\subsection{Decadal-scale variability}

Next, we examine the temporal variability of the relationship between $Z 500$ and SIC with $\delta^{18} 0$ for the extended-winter period. Figure 5a shows the 11-year running correlation between $\delta^{18} \mathrm{O}$ and the Z500 PCs. The $\delta^{18} 0$-SAM correlation is consistently negative until the end of the correlation interval (middle year 2000) when the correlation strength is dramatically reduced. The $\delta^{18} 0-P S A 1$ correlation is stronger than the SAM correlation. The moving $\delta^{18} 0-P S A 1$ correlation is significant at the $p<0.05$ level until 1999 (middle year 2005).

The effective sample size $\left(n_{\text {eff }}\right)$ is larger than the sample size for the $\delta^{18} 0$-SAM correlation (Table 1a). This occurs when the lag-one autocorrelation coefficient of one time series is negative, which is indicative of a blue noise process. We investigate this further by calculating moving average $n_{\text {eff }}$ values for the $\delta^{18} O$ correlation with SAM and PSA1 (Figs. S3a, b). The 11-year mowing window $\delta^{18} 0$-SAM $n_{\text {eff }}$ values become larger than the sample size around the year 2000 (Fig. S3a). This appears to be related to an increased magnitude towards higher frequencies in the SAM PC (Figs. S3c). A similar but subdued increase in $\mathrm{n}_{\text {eff }}$ towards more recent years is also apparent for the $\delta^{18}$ O PSA1 correlation (Fig. S3a). Higher frequency blue noise can occur in $\delta^{18} \mathrm{O}$ records at shallow depths, where the signal has not yet been attenuated by diffusion (Fisher 1985; Fisher et al. 1996). This is ruled out for $\mathrm{RI}^{18} \mathrm{O}$ because it shows low magnitudes of higher-frequency variability close to the snow surface (Fig. S3b). We conclude that the 1990-1991 $\delta^{18} \mathrm{O}$ increase in magnitude during the extended-winter period is driven by the ASL (Fig. $3 b$ ).

The loss in correlation corresponds to an apparent breakdown of the in-phase relationship with $\delta^{18} \mathrm{O}$ (Figs. 3a and 4a). In 2010 a SAM+/PSA- (La Niña) event is associated with a positive $\delta^{18} 0$ anomaly. Additionally, PSA1 is neutral in 2011, yet $\delta^{18} 0$ displays the most positive anomaly during the satellite era. Thus, the running correlation between $\delta^{18} O$ and SAM and between $\delta^{18} O$ and PSA1 is lost. As the PSA1 teleconnection is related to ENSO, the running correlation with Niño-4 SST is also lost (Figs. $5 \mathrm{~d}$ ). Furthermore, as SAM and PSA1 are the dominant drivers of ADP SIC variability the $\delta^{18} \mathrm{O}$ running correlation with ADP is lost. Note, the $\delta^{18} 0$ moving correlation with Niño-4, PSA1, and ADP curves are almost identical. The 11-year mowing window $\delta^{18} \mathrm{O}-\mathrm{Niño}-4$ and $\delta^{18} \mathrm{O}-\mathrm{ADP} \mathrm{n}_{\text {eff }}$ values are smaller than the sample size for the (middle-year) 1995-2004 period (Fig. S3f), indicative of red noise.

The scatter plots in Figure 5 show the linear regression between $\delta^{18} \mathrm{O}$ and the two leading Z500 PCs (Figs. 5b and 5c) and with ADP and central tropical Pacific SSTs (Niño-4; Figs. 5e and 5f). If years 2010 and 2011 are excluded, the $\delta^{18} O$ correlations with SAM and PSA1 remain strong (Figs. 5b, c). Suggesting conditions during 2010-2011 are causing a reduction in correlation strength. The loss of correlation is also evident in the spatial correlation patterns, which bear an even clearer resemblance with the Z500, 
SAT, and SIC in-phase composites when the correlation interval is limited to 1979-2009 (Figs. S4 and $4 b-d)$.

The change in intercept (but not slope) implies that SAM and PSA1 still have the same effect on $\delta^{1} \llbracket 0$ during the extended winter of 2010 and 2011 (red asterixis Figs. 5b, c), but a polynya and/or decadal variability (IPO, change in teleconnection) may have caused the offset in the intercept (red dashed lines in Figs. 5b, c). Polynyas and open ocean adjacent to RICE can provide a source of local maritime air, which can enrich the isotopic signal. This will be a topic for future research.

\section{Summary}

In this study, we demonstrate that for the extended-winter period from April to November, the Roosevelt Island $\delta^{18} \mathrm{O}$ record is correlated with the two leading modes of Southern Hemisphere atmospheric circulation variability, the SAM and PSA1. Importantly, the $\delta^{18} \mathrm{O}$ captures changes in the phase relationship between these two modes, which has been suggested as the driver for recent climate change in West Antarctic and the Antarctic Peninsula (Fogt et al. 2011; Clem and Fogt 2013). For example, the acceleration in West Antarctic snowfall since the 1990s has been attributed to the in-phase relationship of SAM and ENSO (Thomas et al. 2015). At Roosevelt Island, the in-phase relationship is associated with strong atmospheric, sea ice, and SAT anomalies across the Pacific sector of the Southern Ocean, the eastern Ross Sea, and West Antarctica. SAM-/PSA1+ (EI Niño) is associated with positive $\delta^{18} 0$ anomalies while SAM+/PSA1- (La Niña) is associated with negative $\delta^{18} O$ anomalies. RICE $\delta^{18} O$ captures the ENSO-SAM relationship in the Pacific sector of the Southern Ocean and the associated atmospheric circulation, SIC, and SAT extremes. Thus, RICE $\delta^{18} \mathrm{O}$ can be utilized to reconstruct the strength of the ENSO-SAM connection beyond the instrumental period. Potentially to 2,700 years before present (700 B.C.E.), the limit to which the annual-resolved layer counting of the RICE core extend (Winstrup et al. 2017).

\section{Declarations}

\section{Acknowledgements}

We like to acknowledge two anonymous reviewers for their constructive comments, which helped to improve the manuscript. We are also grateful to Christo Buizert who provided comments on an earlier version of this manuscript. This work is a contribution to the Roosevelt Island Climate Evolution (RICE) program. Funding for the RICE project was provided by the New Zealand Ministry of Business, Innovation, and Employment Grants through Victoria University of Wellington (RDF-VUW-1103, 15-VUW-131) and GNS Science (Global Change Through Time Programme). The authors have no conflict of interest to declare.

\section{References}


1. Bertler NAN, Conway H, Dahl-Jensen D, et al (2018) The Ross Sea Dipole - temperature, snow accumulation and sea ice variability in the Ross Sea region, Antarctica, over the past 2700 years. Clim Past 14:193-214. https://doi.org/10.5194/cp-14-193-2018

2. Bracegirdle TJ, Marshall GJ (2012) The Reliability of Antarctic Tropospheric Pressure and Temperature in the Latest Global Reanalyses. J Clim 25:7138-7146. https://doi.org/10.1175/JCLI-D11-00685.1

3. Bretherton CS, Widmann M, Dymnikov VP, et al (1999) Effective number of degrees of freedom of a spatial field. J Clim 12:1990-2009

4. Bromwich DH, Weaver CJ (1983) Latitudinal displacement from main moisture source controls $\delta 180$ of snow in coastal Antarctica. Nature 301:145-147

5. Clem KR, Fogt RL (2013) Varying roles of ENSO and SAM on the Antarctic Peninsula climate in austral spring. J Geophys Res Atmos 118:11481-11492. https://doi.org/10.1002/jgrd.50860

6. Dansgaard W (1964) Stable isotopes in precipitation. Tellus 16:436-468. https://doi.org/10.1111/j.2153-3490.1964.tb00181.x

7. Dee DP, Uppala SM, Simmons AJ, et al (2011) The ERA-Interim reanalysis: configuration and performance of the data assimilation system. Q J R Meteorol Soc 137:553-597. https://doi.org/10.1002/qj.828

8. Deser C, Alexander MA, Xie S-P, Phillips AS (2010) Sea surface temperature variability: Patterns and mechanisms. Ann Rev Mar Sci 2:115-143

9. Ding Q, Steig EJ, Battisti DS, Wallace JM (2012) Influence of the Tropics on the Southern Annular Mode. J Clim 25:6330-6348. https://doi.org/10.1175/JCLI-D-11-00523.1

10. Dommenget D, Latif M (2002) A Cautionary Note on the Interpretation of EOFs. J Clim 15:216-225. https://doi.org/10.1175/1520-0442(2002)015<0216:ACNOTI>2.0.CO;2

11. Ebisuzaki W (1997) A Method to Estimate the Statistical Significance of a Correlation When the Data Are Serially Correlated. J Clim 10:2147-2153. https://doi.org/10.1175/15200442(1997)010<2147:AMTETS>2.0.C0;2

12. Emanuelsson BD, Baisden WT, Bertler NAN, et al (2015) High-resolution continuous-flow analysis setup for water isotopic measurement from ice cores using laser spectroscopy. Atmos Meas Tech 8:2869-2883. https://doi.org/10.5194/amt-8-2869-2015

13. Emanuelsson BD, Bertler NAN, Neff PD, et al (2018) The role of Amundsen-Bellingshausen Sea anticyclonic circulation in forcing marine air intrusions into West Antarctica. Clim Dyn Accepted. https://doi.org/10.1007/s00382-018-4097-3

14. Emanuelsson D (2016) High-Resolution Water Stable Isotope Ice-Core Record: Roosevelt Island, Antarctica: a thesis submitted to the Victoria University of Wellington in fulfilment of the requirements for the degree of Doctor of Philosophy (Geology) / by B. Daniel Emanuelsson. Thesis (Ph.D.)--Victoria University of Wellington, 2016.

15. England M, Polvani L, Sun $L$ (2018) Contrasting the Antarctic and Arctic Atmospheric Responses to Projected Sea Ice Loss in the Late Twenty-First Century. J Clim 31:6353-6370. 
https://doi.org/10.1175/JCLI-D-17-0666.1

16. Fisher D a (1985) Stratigraphic noise in time series derived from ice cores. Ann Glaciol 7:76-83

17. Fisher DA, Koerner RM, Kuivinen K, et al (1996) Inter-comparison of Ice Core $\delta(180)$ and Precipitation Records from Sites in Canada and Greenland over the last 3500 years and over the last few Centuries in detail using EOF Techniques. BT - Climatic Variations and Forcing Mechanisms of the Last 2000 Yea. In: Jones PD, Bradley RS, Jouzel J (eds). Springer Berlin Heidelberg, Berlin, Heidelberg, pp 297328

18. Fogt RL, Bromwich DH, Hines KM (2011) Understanding the SAM influence on the South Pacific ENSO teleconnection. Clim Dyn 36:1555-1576. https://doi.org/10.1007/s00382-010-0905-0

19. Hosking JS, Orr A, Marshall GJ, et al (2013) The Influence of the Amundsen-Bellingshausen Seas Low on the Climate of West Antarctica and Its Representation in Coupled Climate Model Simulations. J Clim 26:6633-6648. https://doi.org/10.1175/JCLI-D-12-00813.1

20. Jin D, Kirtman BP (2009) Why the Southern Hemisphere ENSO responses lead ENSO. J Geophys Res Atmos 114:n/a-n/a. https://doi.org/10.1029/2009JD012657

21. Jones RW, Renfrew IA, Orr A, et al (2016) Evaluation of four global reanalysis products using in-situ observations in the Amundsen Sea Embayment, Antarctica. J Geophys Res Atmos n/a-n/a. https://doi.org/10.1002/2015JD024680

22. Karoly DJ (1989) Southern Hemisphere Circulation Features Associated with El Niño-Southern Oscillation Events. J Clim 2:1239-1252. https://doi.org/10.1175/15200442(1989)002<1239:SHCFAW>2.0.C0;2

23. Kidson JW (1988) Interannual Variations in the Southern Hemisphere Circulation. J. Clim. 1:939-953

24. Küttel M, Steig EJ, Ding Q, et al (2012) Seasonal climate information preserved in West Antarctic ice core water isotopes: relationships to temperature, large-scale circulation, and sea ice. Clim Dyn 39:1841-1857. https://doi.org/10.1007/s00382-012-1460-7

25. Lim E-P, Hendon HH (2017) Causes and Predictability of the Negative Indian Ocean Dipole and Its Impact on La Niña During 2016. Sci Rep 7:12619. https://doi.org/10.1038/s41598-017-12674-z

26. Marshall GJ, Thompson DWJ (2016) The signatures of large-scale patterns of atmospheric variability in Antarctic surface temperatures. J Geophys Res Atmos 121:3276-3289. https://doi.org/10.1002/2015JD024665

27. Masson-Delmotte V, Hou S, Ekaykin a., et al (2008) A review of antarctic surface snow isotopic composition: Observations, atmospheric circulation, and isotopic modeling. J Clim 21:3359-3387. https://doi.org/10.1175/2007JCLI2139.1

28. Mo KC, Higgins RW (1998) The Pacific-South American Modes and Tropical Convection during the Southern Hemisphere Winter. Mon Weather Rev 126:1581-1596. https://doi.org/10.1175/15200493(1998)126<1581:TPSAMA>2.0.CO;2

29. Monahan AH, Fyfe JC, Ambaum MHP, et al (2009) Empirical Orthogonal Functions: The Medium is the Message. J Clim 22:6501-6514. https://doi.org/10.1175/2009JCLI3062.1 
30. Noone D, Simmonds I (2004) Sea ice control of water isotope transport to Antarctica and implications for ice core interpretation. J Geophys Res 109:1-13.

https://doi.org/10.1029/2003JD004228

31. Noone D, Simmonds I (2002) Annular variations in moisture transport mechanisms and the abundance of $\delta 180$ in Antarctic snow. J Geophys Res Atmos 107:ACL 3-1-ACL 3-11. https://doi.org/10.1029/2002JD002262

32. North GR, Bell TL, Cahalan RF, Moeng FJ (1982) Sampling Errors in the Estimation of Empirical Orthogonal Functions. Mon Weather Rev 110:699-706. https://doi.org/10.1175/15200493(1982)110<0699:SEITEO>2.0.C0;2

33. Raphael MN, Marshall GJ, Turner J, et al (2015) The Amundsen Sea Low: Variability, Change and Impact on Antarctic Climate. Bull Am Meteorol Soc. https://doi.org/10.1175/BAMS-D-14-00018.1

34. Rayner NA, Parker DE, Horton EB, et al (2003) Global analyses of sea surface temperature, sea ice, and night marine air temperature since the late nineteenth century. J Geophys Res Atmos 108:1-37. https://doi.org/10.1029/2002JD002670

35. Renwick JA (2002) Southern Hemisphere Circulation and Relations with Sea Ice and Sea Surface Temperature. J Clim 15:3058-3068. https://doi.org/10.1175/15200442(2002)015<3058:SHCARW>2.0.C0;2

36. Richman MB (1986) Rotation of principal components. J Climatol 6:293-335. https://doi.org/10.1002/joc.3370060305

37. Rogers JC, van Loon H (1982) Spatial Variability of Sea Level Pressure and $500 \mathrm{mb}$ Height Anomalies over the Southern Hemisphere. Mon Weather Rev 110:1375-1392. https://doi.org/10.1175/1520-0493(1982)110<1375:SVOSLP>2.0.C0;2

38. Schneider DP, Okumura Y, Deser C (2012) Observed Antarctic Interannual Climate Variability and Tropical Linkages. J Clim 25:4048-4066. https://doi.org/10.1175/JCLI-D-11-00273.1

39. Sinclair KE, Bertler NAN, Bowen MM, Arrigo KR (2014) Twentieth century sea-ice trends in the Ross Sea from a high-resolution, coastal ice-core record. Geophys Res Lett 41:3510-3516. https://doi.org/10.1002/2014GL059821

40. Steig EJ, Ding Q, White JWC, et al (2013) Recent climate and ice-sheet changes in West Antarctica compared with the past 2,000 years. Nat Geosci 6:372-375

41. Steig EJ, Schneider DP, Rutherford SD, et al (2009) Warming of the Antarctic ice-sheet surface since the 1957 International Geophysical Year. Nature 457:459-462

42. Stenni B, Curran MAJ, Abram NJ, et al (2017) Antarctic climate variability on regional and continental scales over the last 2000 years. Clim Past 13:1609-1634. https://doi.org/10.5194/cp-13-1609-2017

43. Storch H Von, Zwiers FW (1999) Statistical Analysis in Climate Research. J Am Stat Assoc 95:1375. https://doi.org/10.1017/CB09780511612336

44. Thomas ER, Abram NJ (2016) Ice core reconstruction of sea ice change in the Amundsen-Ross Seas since 1702 A.D. Geophys Res Lett 43:5309-5317. https://doi.org/10.1002/2016GL068130 
45. Thomas ER, Hosking JS, Tuckwell RR, et al (2015) Twentieth century increase in snowfall in coastal West Antarctica. Geophys Res Lett 42:9387-9393.

https://doi.org/https://doi.org/10.1002/2015GL065750

46. Thompson DWJ, Wallace JM (2000) Annular Modes in the Extratropical Circulation. Part I: Month-toMonth Variability*. J Clim 13:1000-1016. https://doi.org/10.1175/15200442(2000)013<1000:AMITEC>2.0.C0;2

47. Tuohy A, Bertler N, Neff P, et al (2015) Transport and deposition of heavy metals in the Ross Sea Region, Antarctica. J Geophys Res Atmos 120:10,11,911-996. https://doi.org/10.1002/2015JD023293

48. Turner J (2004) The El Niño-Southern Oscillation and Antarctica. Int J Climatol 24:1-31. https://doi.org/10.1002/joc.965

49. Turner J, Comiso JC, Marshall GJ, et al (2009) Non-annular atmospheric circulation change induced by stratospheric ozone depletion and its role in the recent increase of Antarctic sea ice extent. Geophys Res Lett 36:1-5. https://doi.org/10.1029/2009GL037524

50. Turner J, Phillips T, Hosking JS, et al (2013) The Amundsen Sea low. Int J Climatol 33:1818-1829. https://doi.org/10.1002/joc.3558

51. Westra S, Renard B, Thyer M (2015) The ENSO-Precipitation Teleconnection and Its Modulation by the Interdecadal Pacific Oscillation. J Clim 28:4753-4773. https://doi.org/10.1175/JCLI-D-1400722.1

52. Wilks DS (2006) On "Field Significance" and the False Discovery Rate. J Appl Meteorol Climatol 45:1181-1189. https://doi.org/10.1175/JAM2404.1

53. Wilks DS (2017) "The Stippling Shows Statistically Significant Grid Points": How Research Results are Routinely Overstated and Overinterpreted, and What to Do about It. Bull Am Meteorol Soc 97:2263-2273. https://doi.org/10.1175/BAMS-D-15-00267.1

54. Winstrup M, Vallelonga PT, Kjær H a., et al (2017) A 2700-year timescale and accumulation reconstruction for Roosevelt Island, West Antarctica. Clim Past Discuss submitted

55. Yu J-Y, Paek H, Saltzman ES, Lee T (2015) The Early 1990s Change in ENSO-PSA-SAM Relationships and Its Impact on Southern Hemisphere Climate. J Clim 28:9393-9408. https://doi.org/10.1175/JCLI-D-15-0335.1

56. Yuan X (2004) ENSO-related impacts on Antarctic sea ice: a synthesis of phenomenon and mechanisms. Antarct Sci 16:415-425. https://doi.org/DOI: 10.1017/S0954102004002238

57. Yuan X, Martinson DG (2000) Antarctic Sea Ice Extent Variability and Its Global Connectivity. J Clim 13:1697-1717. https://doi.org/10.1175/1520-0442(2000)013<1697:ASIEVA>2.0.C0;2

\section{Tables}

Due to technical limitations, table 1 is only available as a download in the Supplemental Files section. 
Figures

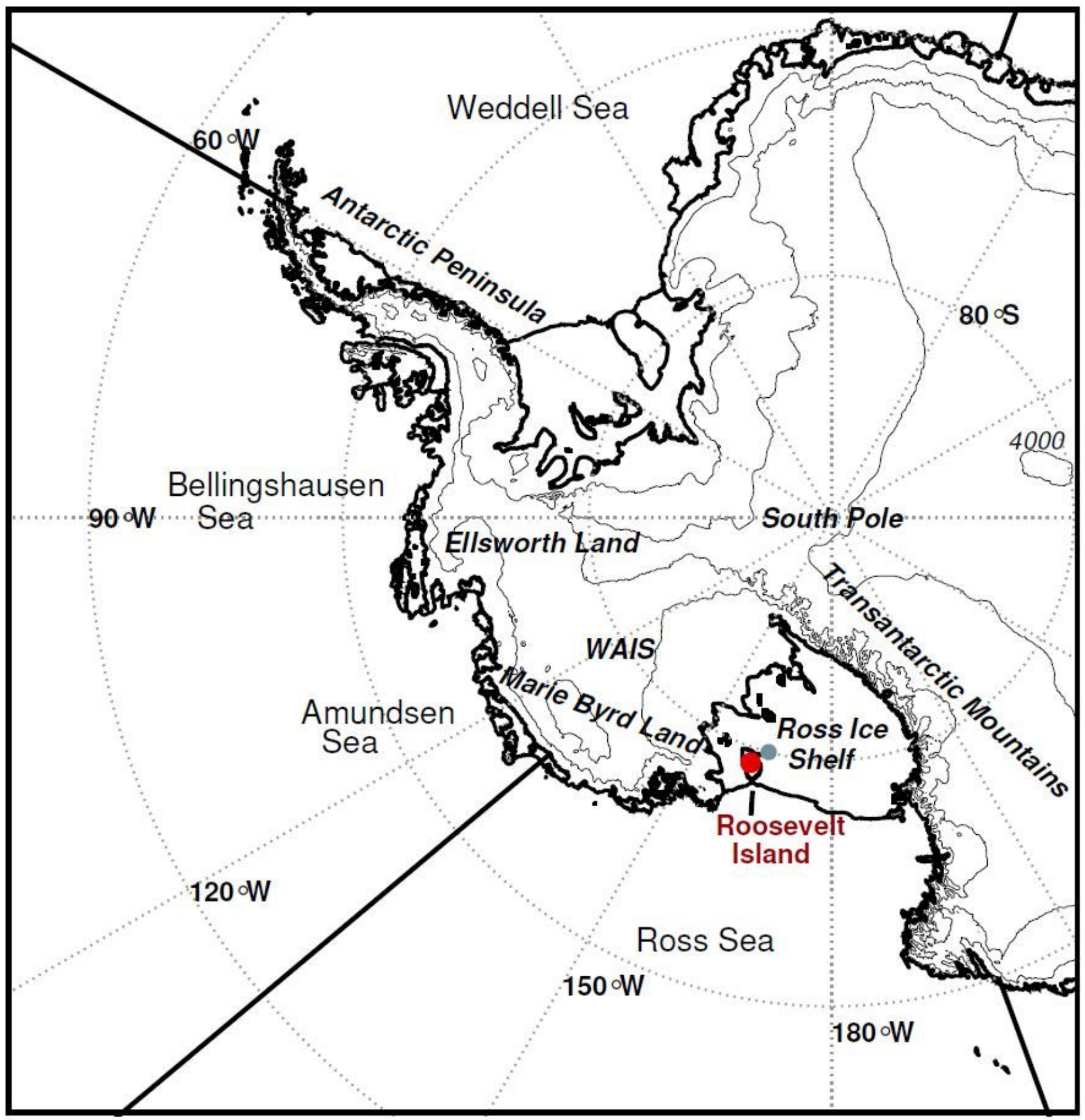

Figure 1

(a) Antarctica location map. Roosevelt Island ice core drill site (RICE, red dot) and Margaret AWS (grey dot); Contours (thin black lines) with 1,000 m spacing indicate elevation above sea level. Thick black lines depict the boundaries for the main Antarctic seas. 

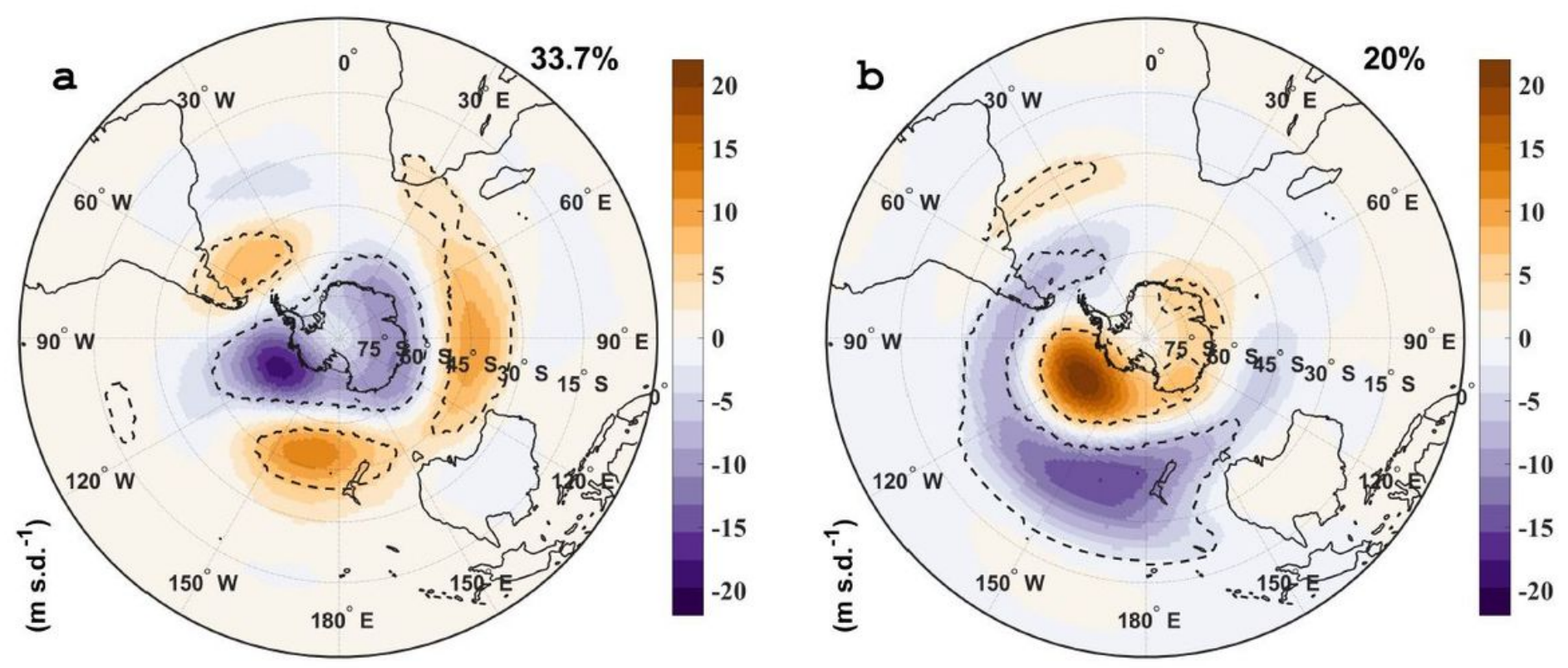

\section{Figure 2}

The two leading SH large-scale atmospheric circulation patterns [shading, meter per standard deviation of the index (m s.d. $\left.\left.{ }^{-1}\right), 1979-2011\right]$. Extended winter seasonally-averaged monthly 500-hPa geopotential height anomaly fields are regressed onto (b) the leading PC, SAM; and (c) the second PC, PSA1. All the circulation patterns are shown during their positive polarities. We use the same polarity sign convention for the positive phase of the PSA1 pattern as Kidson (1988) (his figure 4b). 


\section{a}
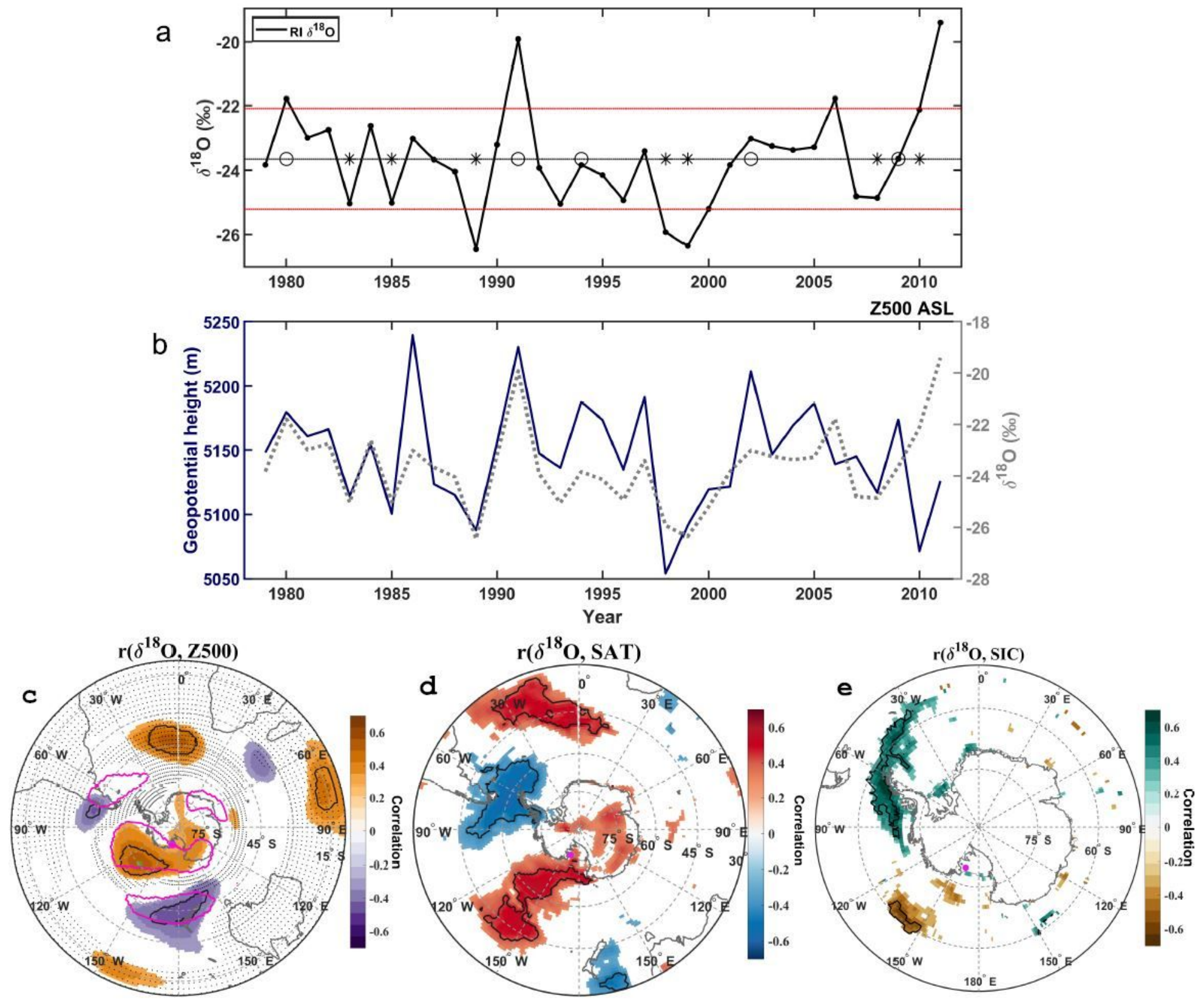

Figure 3

(a) RICE extended-winter $\delta^{18} 0$ record, 1979-2011. The grey horizontal line shows the mean and redlines the \pm 1 standard deviation. Positive SAM/negative PSA1 years are indicated by asterisks and negative SAM/positive PSA1 years are indicated by circles (defined in Fig. 4a). (b) Mean extended-winter season ASL 500-hPa geopotential height ( $\mathrm{m}$, blue line), extracted from the point of maximum correlation. The RICE $\delta^{18} O$ for the 1979-2011 period is repeated (gray dotted line) (c-e) Correlation maps for the extended-winter season (1979-2011) between RICE $\delta^{18} 0$ and ERA-Interim (c) Z500, (d) SAT, and (e) HadISST SIC. Correlation coefficients ( $r, p<0.1$, shading) and the $p<0.05$ confidence level (black contours). (c) Areas, where both SAM- and PSA1-Z500 regression patterns (shown in Figs. 2a and 2b) are significant, are contoured; enclosing regions where both modes display the same sign (magenta contours) when in-phase (or opposing sign when out of phase). The stippled areas indicate regions where 
none of the patterns displays a significant pattern. The RICE drill site is indicated by a magenta dot and the point of maximum correlation in $\mathrm{c}$ is indicated by a green dot.
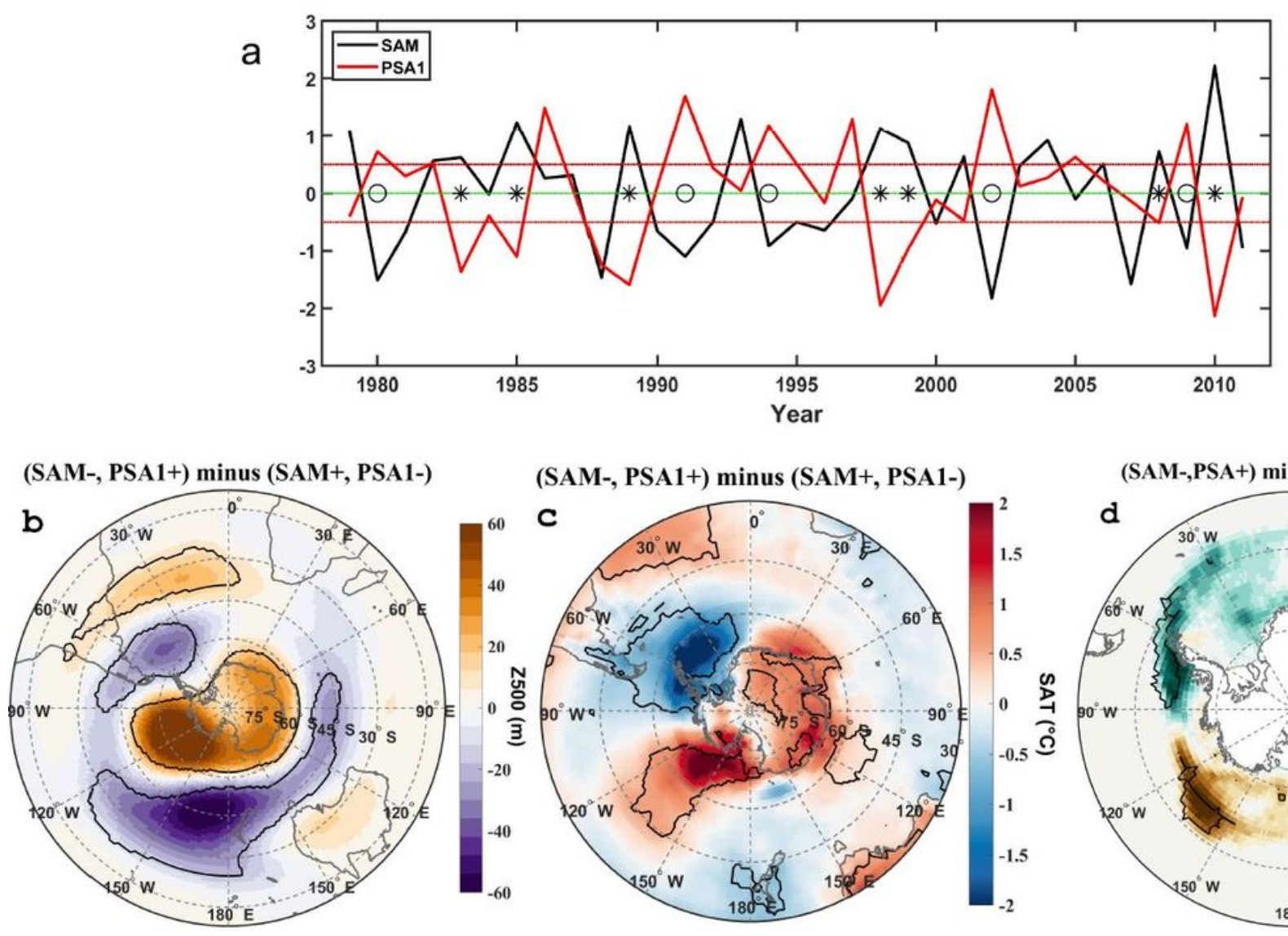

(SAM-, PSA1+) minus (SAM+, PSA1-)
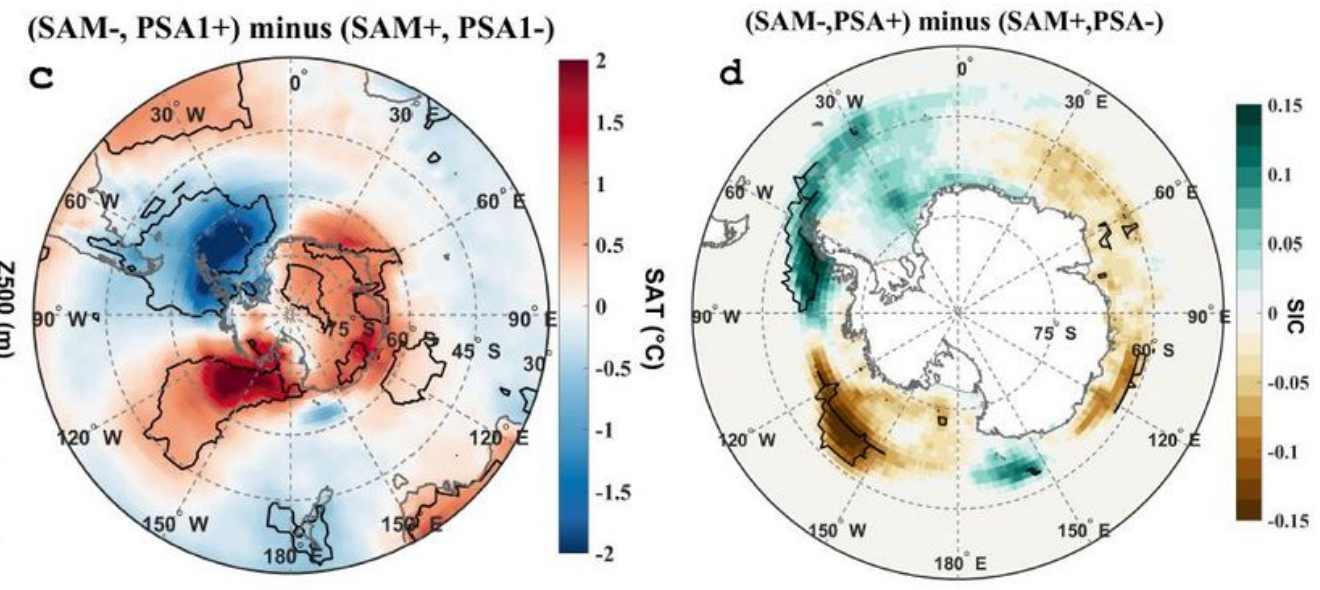

\section{Figure 4}

(a) The SAM and PSA1 PC time series. Positive SAM/negative PSA1 years are indicated by asterisks and negative SAM/positive PSA1 years are indicated by circles. Horizontal red and black lines indicate the \pm 0.5 standard deviation threshold that is used for in-phase event identification. (b-d) Composite differences, negative SAM/positive PSA1 minus positive SAM/negative PSA years, for (b) Z500, (c) SAT, and (d) SIC. The $p<0.05$ confidence level is indicated by black contours. 

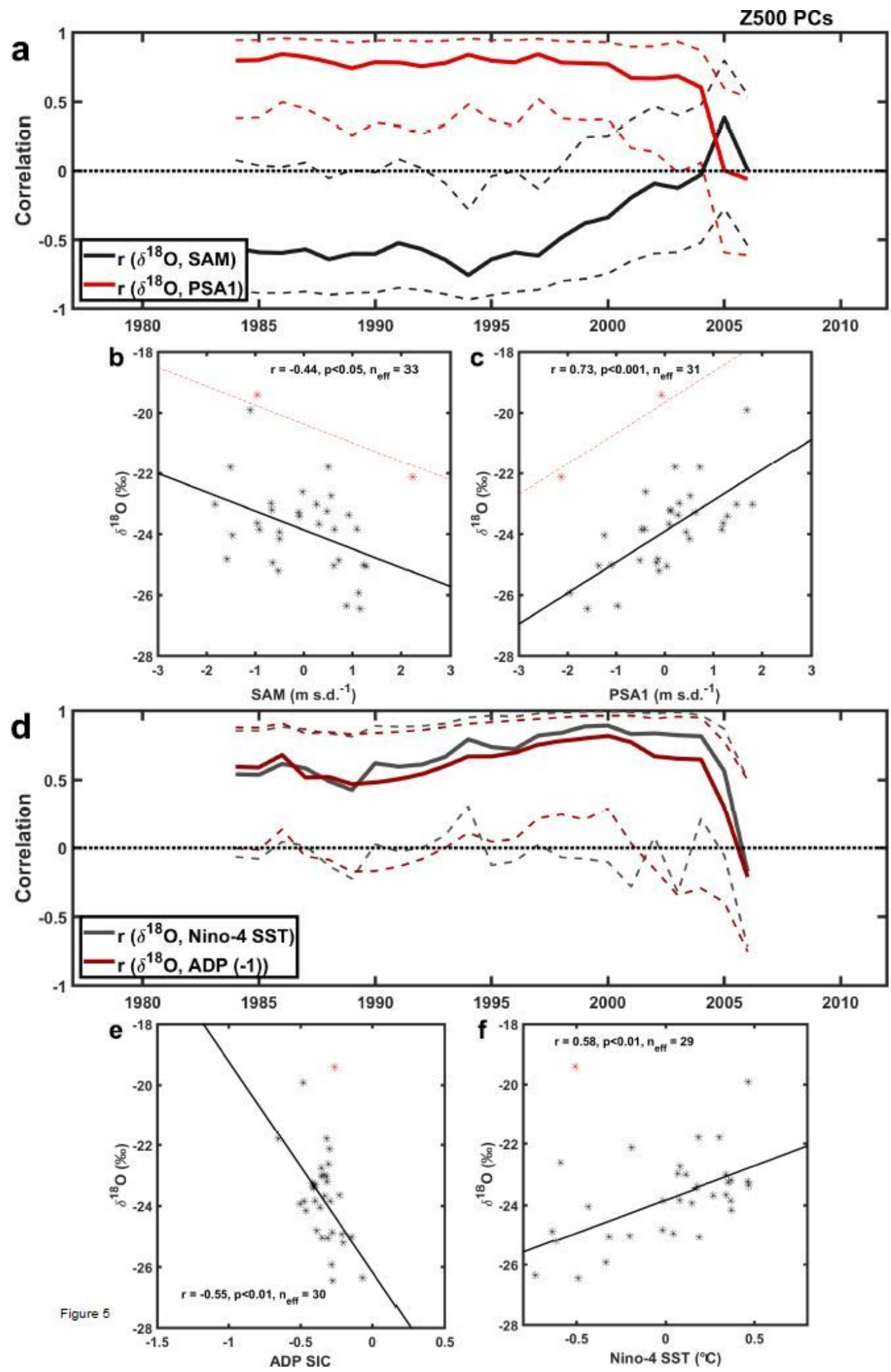

Figure 5

(a) Eleven-year moving correlation of RICE $\delta^{18} 0$ with the Z500 PC1 (SAM, black line) and PC2 (PSA1, red line). Dashed curves give the $p<0.05$ confidence intervals. Scatter plots of the Z500 PCs, (b) PC1 SAM and (c) PC2 PSA1 with $\delta^{18} 0$. Linear regressions, correlation coefficients $(r)$, significance level $(p)$ and effective sample size $\left(\mathrm{n}_{\text {eff }}\right)$ are provided for each panel. The analysis for $(b, c)$ does not include the years 2010 and 2011, indicated by red asterisks. The red dashed lines have the same slope as the main linear 
regression but with an added offset to the intercept. (d) same as a, but for the Antarctic Dipole sea ice index (ADP, red line) and annually-averaged central Pacific SST anomalies $\left(5^{\circ} \mathrm{S}-5^{\circ} \mathrm{N}, 160^{\circ} \mathrm{E}-150^{\circ} \mathrm{W}\right)$, Niño-4 (grey line). (e,f) Scatter plots between the ADP and $\delta^{18} O$ and between Niño-4 SSTs and $\delta^{18} O$. The analysis for $e$ and $f$ does not include the year 2011 , indicated by red asterisks.

\section{Supplementary Files}

This is a list of supplementary files associated with this preprint. Click to download.

- Table1.jpg

- EmanuelssonetalClimDynSuppIMaterial29122022combined.pdf 